\author{
CARRIE RITCHIE, PhD 1 • JOAN HENDRIKZ, PGradStats ${ }^{2}$ • GWENDOLEN JULL, PhD ${ }^{3}$ \\ JAMES ELLIOTT, $\mathrm{PhD}^{4}$ • MICHELE STERLING, PhD ${ }^{1}$
}

\title{
External Validation of a Clinical Prediction Rule to Predict Full Recovery and Ongoing Moderate/Severe Disability Following Acute Whiplash Injury
}

STUDY DESIGN: Retrospective secondary analysis of data.

OBJECTIVES: To investigate the external validity of the whiplash clinical prediction rule (CPR).

BACKGROUND: We recently derived a whiplash CPR to consolidate previously established prognostic factors for poor recovery from a whiplash injury and predicted 2 recovery pathways. Prognostic factors for full recovery were being less than 35 years of age and having an initial Neck Disability Index (NDI) score of $32 \%$ or less. Prognostic factors for ongoing moderate/severe pain and disability were being 35 years of age or older, having an initial NDI score of $40 \%$ or more, and the presence of hyperarousal symptoms. Validation is required to confirm the reproducibility and accuracy of this CPR. Clinician feedback on the usefulness of the CPR is also important to gauge acceptability.

METHODS: A secondary analysis of data from 101 individuals with acute whiplash-associated disorder who had previously participated in either a randomized controlled clinical trial or prospective cohort study was performed using accuracy statistics. Full recovery was defined as NDI score at 6 months of $10 \%$ or less, and ongoing moderate/ severe pain and disability were defined as an NDI score at 6 months of $30 \%$ or greater. In addition, a small sample of physical therapists completed an anonymous survey on the clinical acceptability and usability of the tool.

- RESULTS: The positive predictive value of ongoing moderate/severe pain and disability was $90.9 \%$ in the validation cohort, and the positive predictive value of full recovery was $80.0 \%$. Surveyed physical therapists reported that the whiplash CPR was simple, understandable, would be easy to use, and was an acceptable prognostic tool.

CONCLUSION: External validation of the whiplash CPR confirmed the reproducibility and accuracy of this dual-pathway tool for individuals with acute whiplash-associated disorder. Further research is needed to assess prospective validation, the impact of inclusion on practice, and to examine the efficacy of linking treatment strategies with predicted prognosis.

- LEVEL OF EVIDENCE: Prognosis, level $1 \mathrm{~b}$. J Orthop Sports Phys Ther 2015;45(4):242-250. doi:10.2519/jospt.2015.5642

KEY WORDS: Neck Disability Index, prediction, prognosis, whiplash-associated disorder

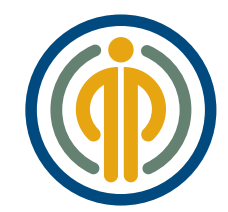

$\mathbf{U}$ nderstanding recovery pathways and optimal treatment for individuals with whiplash-associated disorder (WAD) continues to be a challenge. Over the past few decades, recovery rates have remained unchanged, with approximately 50\% of individuals continuing to experience ongoing pain and disability at 6 months postinjury. ${ }^{14,32}$ Given the personal and societal burden associated with this longterm disability, research has focused on early identification of individuals at risk of ongoing symptoms to help understand recovery pathways and subsequently develop more targeted treatments. ${ }^{32}$

${ }^{1}$ Menzies Health Institute Queensland, Centre for National Research on Disability and Rehabilitation Medicine (CONROD), Griffith University, Gold Coast, Australia. ${ }^{2}$ Centre for National Research on Disability and Rehabilitation Medicine, University of Queensland, Brisbane, Australia. ${ }^{3}$ Division of Physiotherapy, School of Health and Rehabilitation Sciences, Centre for Clinical Research Excellence in Spinal Pain, Injury and Health, University of Queensland, Brisbane, Australia. ${ }^{4}$ Department of Physical Therapy and Human Movement Sciences, Feinberg School of Medicine, Northwestern University, Chicago, IL. The study protocol was approved by the University of Queensland Medical Research Ethics Committee. Funding for this study was received from the National Health and Medical Research Council Project Grant (number 351408) and the Physiotherapy Research Foundation (Australia). Professor Sterling receives a research fellowship from the National Health and Medical Research Council, Australia. Her appointment is also funded from an unrestricted grant from the Motor Accident Insurance Commission (MAIC) to Griffith University. Dr Ritchie and Ms Hendrikz's appointments are funded from an unrestricted grant from the MAIC to Griffith University and the University of Queensland. The MAIC is a statutory government body established under the Motor Accident Insurance Act (1994) to regulate the Compulsory Third Party compensation scheme in Queensland, Australia. The MAIC is not a commercial entity. The authors certify that they have no affiliations with or financial involvement in any organization or entity with a direct financial interest in the subject matter or materials discussed in the article. Address correspondence to Professor Michele Sterling, Menzies Health Institute Queensland, Centre for National Research on Disability and Rehabilitation Medicine (CONROD), Griffith University, Gold Coast, QLD 4222 Australia. E-mail: m.sterling@griffith.edu.au • Copyright @2015 Journal of Orthopaedic \& Sports Physical Therapy ${ }^{\circledR}$ 
We recently derived a whiplash clinical prediction rule (CPR) that consolidated previously identified prognostic factors for poor recovery following whiplash injury to predict 2 recovery pathways: full recovery and ongoing moderate/severe pain and disability (FIGURE). ${ }^{26}$

Prognostic CPRs quantify the contributions of relevant prognostic factors to calculate a numeric predicted probability of the outcome of interest. ${ }^{1,19}$ Clinical prediction rules are developed using rigorous methodological standards and have the potential to help clinicians make decisions regarding prognosis and researchers develop targeted therapies. ${ }^{12,25}$ Methodological standards exist for each step in the development of a CPR: derivation, validation, and impact analysis. ${ }^{1,19,25}$ While the derivation of a CPR provides information about potentially important prognostic factors, the validation process ensures that associations between given predictors and outcomes are not primarily due to chance and are not unique to the derivation population. ${ }^{19,29}$ Without validation, the decision to incorporate CPRs into clinical practice is potentially premature. ${ }^{2,11,29}$ Many statistically derived CPRs are not validated, and those that are validated often fail to perform adequately when tested in a new population. ${ }^{1,2,11,29}$

The process for the derivation of the dual-pathway whiplash CPR followed methodological recommendations. ${ }^{26}$ The positive predictive value (PPV) for ongoing moderate/severe pain and disability was $71 \%$ in patients who were 35 years or older, reported initially higher levels of neck disability (Neck Disability Index [NDI] score of $40 \%$ or greater), and reported hyperarousal symptoms of 6 or greater on the hyperarousal subscale of the Posttraumatic Stress Diagnostic Scale (PDS), a substantial increase from the estimated $25 \%$ indicated in previous research. ${ }^{7,15,27,28}$ In addition, meeting the simple criteria of an NDI score of $32 \%$ or lower and an age of less than 35 years in the acute phase provided an estimated probability of full recovery of $71 \%$, an increase from $50 \%$ indicated in previous research. ${ }^{3,15,27}$ To ensure that the CPR is accurate and reproducible, the next step in the development of the whiplash CPR is external validation..$^{1,4,25,29}$

Methodological standards for the validation of a CPR include the use of a series of studies across varied environments. ${ }^{11,19,25}$ Initial external validation includes application of the CPR to a new patient population. Subsequent validation studies may include prospective application in new clinical settings by clinicians different from those involved in the derivation study. ${ }^{1,19,29}$ Evaluation of the CPR's clinical usefulness and acceptability is also important. ${ }^{1,17,33}$ The primary aim of the present study was to investigate the external validity of the whiplash CPR. The secondary aim was to gather preliminary feedback from clinicians about the acceptability and usability of the tool.

\section{METHODS}

A SECONDARY ANALYSIS OF DATA from 2 cohorts independent of the derivation cohort was performed to investigate the external validity of the recently developed dual-pathway whiplash CPR (FIGURE). ${ }^{26}$ Both cohorts were recruited in Brisbane, Australia, ethical approval was gained from the University of Queensland Medical Research Ethics Committee, and all participants provided signed informed consent. ${ }^{7,14}$

\section{Participants With WAD}

Information regarding inclusion and exclusion criteria and procedures for the 2 primary cohort studies have been published previously. ${ }^{7,14}$ All participants for the primary cohort studies were recruited from accident and emergency departments, through referral by primary care practitioners (eg, general practitioners and physical therapists), and through advertising in the popular press. Volunteers for the primary cohort studies were eligible if they were between 18 and 65 years of age and had acute neck pain (less than 4 weeks in duration) as a result of a motor vehicle collision that was classifi- able as WAD grade II. Volunteers were ineligible if their neck pain was not related to a motor vehicle collision or was classifiable as WAD grades I, III, or IV; if there was a previous history of whiplash or other neck pain for which treatment had been sought; or if they lacked fluency in spoken and written English for questionnaire completion.

Cohort 1 was from a prospective longitudinal study that examined prognostic factors for poor functional recovery following a whiplash injury. ${ }^{7}$ The design of the study adhered to STROBE criteria for cohort studies. ${ }^{30}$ Cohort 2 comprised participants from the control intervention (usual care) of a randomized controlled clinical trial. ${ }^{14}$ The trial was registered with the Australian New Zealand Clinical Trials Registry (ACTRN12605000109606). The randomized controlled clinical trial evaluated the effectiveness of individualized multiprofessional management (medical, physiotherapeutic, psychological) compared with usual care. Although the pragmatic multidisciplinary interventions tested in this trial produced no advantage over usual care, to avoid the potential influence of targeted therapy, only the participants receiving usual care (control group) were included within the current validation study.

\section{Whiplash CPR}

The whiplash CPR predicts 2 recovery pathways following an acute whiplash injury: ongoing moderate/severe pain and disability were predicted in the presence of baseline NDI scores of $40 \%$ or greater, age of 35 years or older, and a hyperarousal subscale symptom score on the PDS of 6 or greater. Full recovery was predicted in individuals less than 35 years of age with a baseline NDI score of $32 \%$ or less. ${ }^{26}$

The method used for the derivation of the whiplash CPR has been explained previously. ${ }^{26}$ Briefly, the NDI was the dependent variable. The NDI is a valid, reliable, and responsive measure. ${ }^{31}$ An overall score (out of 100) is calculated by 


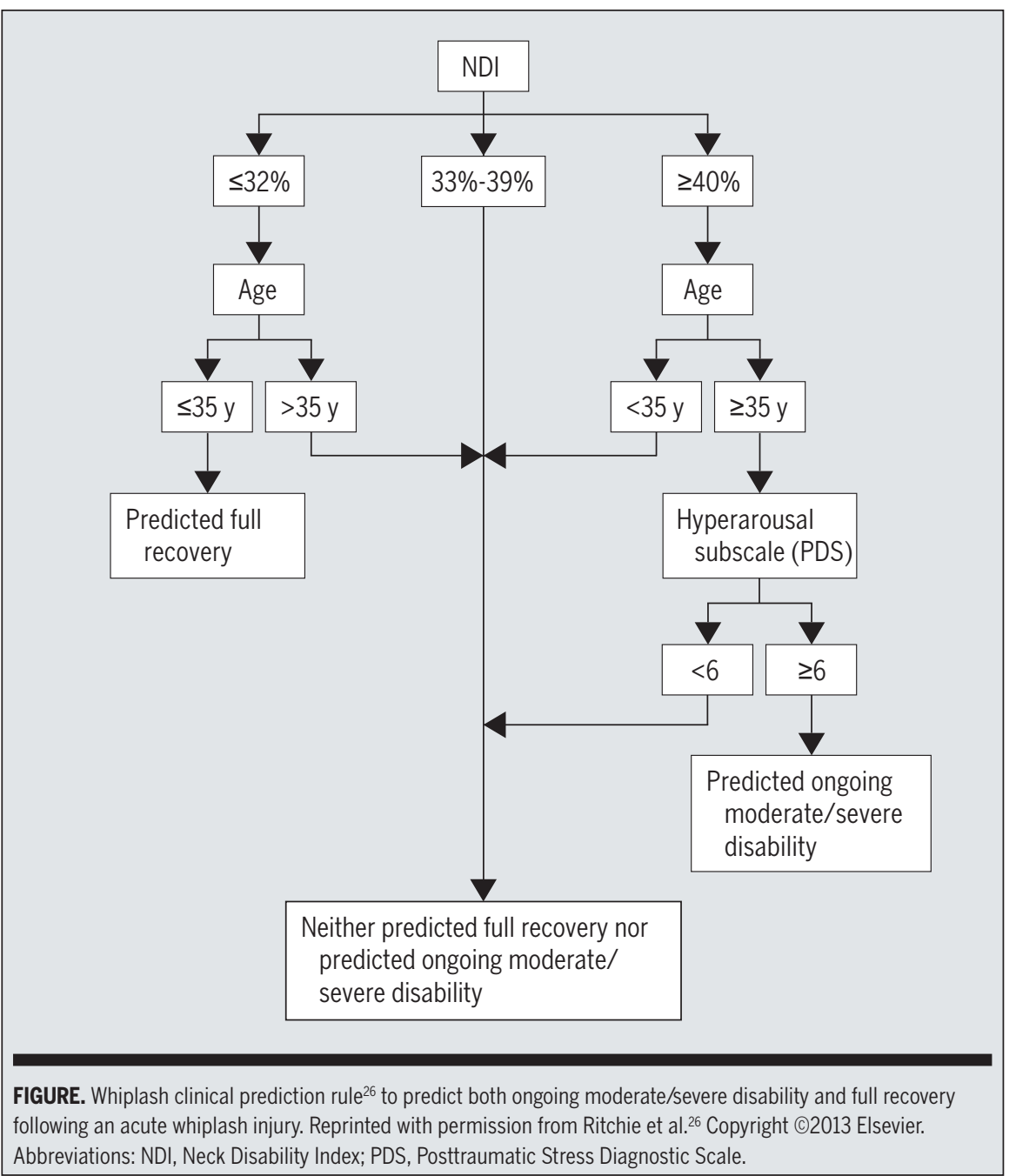

totaling responses to 10 questions, each with 6 potential Likert-type responses ( 0 is no disability and 5 is total disability), and multiplying the sum by 2 to yield a percentage. Previous research has suggested that an NDI score of $30 \%$ or greater is indicative of moderate to severe levels of pain-related disability and that an NDI score of $10 \%$ or less indicates full recovery. ${ }^{18,28}$ In the present study, these criteria were used with the NDI measured at 6 months to classify participants as experiencing ongoing moderate/severe pain and disability (NDI, $30 \%$ or greater), continued mild to moderate pain and disability (NDI, $11 \%-29 \%$ ), or fully recovered (NDI, $10 \%$ or less).

The derivation of the whiplash CPR included analysis of 8 biopsychosocial variables shown in previous research to be predictive of recovery following a whiplash injury: initial NDI, age, cold pain threshold, initial neck pain (visual analog scale [VAS]), neck range of movement, posttraumatic stress symptoms, sex, and presence of headache. ${ }^{15,27,28,32}$ Predictor variables were measured at baseline. ${ }^{26}$

Briefly, measurement methods were age measured in years, cold pain thresholds measured over the mid cervical spine using the THERMOTEST system (Somedic Production AB, Sollentuna, Sweden), ${ }^{28}$ neck pain measured using an 11-point VAS with anchors of 0 (no pain) and 10 (worst pain imaginable), and range of movement calculated as total neck rotation (the sum of left and right neck rotation, flexion, and extension) from measurements using an electromagnetic motion-tracking device (FASTRAK; Polhemus Inc, Colchester, VT). Sex failed to meet statistical significance within the derivation study, and presence of headache was measured differently in the validation cohorts, hence both of these variables were omitted from the present study.

Posttraumatic stress symptoms were measured using the valid and reliable 49item PDS. ${ }^{8}$ Following a standard multiple regression, only the hyperarousal subscale of the PDS (5 items) was found to be significantly predictive and hence was the only subscale included in the derivation analyses and, subsequently, in the present study. The hyperarousal subscale includes questions about trouble sleeping, irritability, difficulties concentrating, being overly alert, and being easily startled. Frequency of symptoms is assessed for each question using a Likerttype format, with options ranging from 0 (not at all or only 1 time) to 3 (5 or more times a week/almost always), resulting in a subscale score of 0 to 15 .

\section{Preliminary Feedback: Clinician Acceptability}

Practitioners who might decide to use this tool in the future were asked to give preliminary feedback about its clinical acceptability and usefulness. Although not totally representative of clinicians who might treat individuals with an acute whiplash injury, a few groups were selected that represented clinicians who had and had not been involved in clinical research trials involving whiplash injuries. These groups included physical therapists practicing in Queensland, Australia who were titled "musculoskeletal physiotherapists" by the Australian Physiotherapy Association and whose contact e-mail details were available to the public $(\mathrm{n}=74)$; chiropractors registered with the Chiropractors' Association of Australia practicing in Queensland, Australia whose contact details were available to the public $(\mathrm{n}=61)$; and physical therapists identified as experts in the area of 
whiplash research from Perth and Melbourne, Australia, and Canada $(\mathrm{n}=10)$.

A written format of the whiplash CPR with instructions for use and an anonymous survey were sent via e-mail. The survey collected background information on number of patients with whiplash seen each month and included Likerttype questions about the acceptability and usability of the whiplash CPR. Openended questions collected information on preferred mode of delivery, benefits and disadvantages of the whiplash CPR, and potential difficulties in using this type of tool. A reminder e-mail was sent 10 days after the initial request.

It was understood that interpretation of feedback would be limited because clinicians had not yet used the tool with patients. Despite this, we felt it important to seek some feedback before embarking on the next stage of CPR development, which was prospective evaluation followed by evaluation of impact on practice. If there were concerns about the content, acceptability, and/or usability, changes to the tool would be needed. Ethical approval was granted by the University of Queensland Medical Research Ethics Committee (number 2013000671).

\section{Data Analysis}

The predictive ability of the whiplash CPR to identify those likely to fully recover and those likely to experience ongoing moderate/severe pain and disability was assessed using accuracy statistics for the positive case (specificity, sensitivity, likelihood ratios [LRs], PPV) with $95 \%$ confidence intervals (CIs). Validation accuracy for identification purposes was assessed using revised estimates of the probability (PPV) of participants from the validation cohort who were likely to experience ongoing moderate/severe pain and disability or likely to fully recover, using the CPR. ${ }^{26}$ The Hosmer-Lemeshow statistic was used to evaluate the appropriateness of the whiplash CPR models, in which a nonsignificant test indicates good model fit. ${ }^{20}$

Several analyses were also performed to compare the validation study popula-

\begin{tabular}{|c|c|c|}
\hline \multirow[t]{2}{*}{ TABLE 1} & \multicolumn{2}{|c|}{$\begin{array}{c}\text { Accuracy Statistics for Ongoing Moderate/ } \\
\text { Severe Pain and Disability for the } \\
\text { Validation and Derivation Populations* }\end{array}$} \\
\hline & Validation Population & Derivation Population \\
\hline Sensitivity & $43.5(22.9,65.1)$ & $43.5(31.8,54.9)$ \\
\hline Specificity & $98.7(92.9,99.9)$ & $93.8(89.1,96.6)$ \\
\hline Positive likelihood ratio & $33.9(4.6,251.2)$ & $7.0(3.8,12.9)$ \\
\hline Negative likelihood ratio & $0.6(0.4,0.8)$ & $0.6(0.5,0.7)$ \\
\hline Positive predictive value & $90.9(58.7,98.5)$ & $71.4(55.1,83.8)$ \\
\hline
\end{tabular}

\begin{tabular}{|c|c|c|}
\hline \multirow[t]{2}{*}{ TABLE 2} & \multicolumn{2}{|c|}{$\begin{array}{c}\text { Accuracy Statistics For the } \\
\text { Likelihood of Full Recovery for the } \\
\text { Validation and Derivation Populations* }\end{array}$} \\
\hline & Validation Population & Derivation Population \\
\hline Sensitivity & $54.9(40.5,68.6)$ & $45.3(35.1,54.4)$ \\
\hline Specificity & $86.0(72.6,93.7)$ & $84.5(77.3,89.8)$ \\
\hline Positive likelihood ratio & $3.9(1.9,8.1)$ & $2.9(1.9,4.5)$ \\
\hline Negative likelihood ratio & $0.5(0.4,0.7)$ & $0.6(0.5,0.8)$ \\
\hline Positive predictive value & $80.0(62.5,91.7)$ & $70.7(58.9,80.3)$ \\
\hline
\end{tabular}

tion with the derivation study population. First, $t$ tests and chi-square analyses for independent samples were performed to identify any statistically significant differences in terms of 6 of the 8 possible predictor variables investigated for the CPR in the derivation study (eg, initial NDI, neck pain VAS, age, range of movement, cold pain threshold, hyperarousal). An additional chi-square analysis was performed to determine whether possible differences in recovery rates existed between the 2 study populations: specifically, differences in the proportion of participants who were classified at 6 months as being fully recovered (NDI, $10 \%$ or less), continuing to experience mild to moderate levels of disability (NDI, 11\%-29\%), and having ongoing moderate/severe disability (NDI, 30\% or greater).

Second, $t$ tests and chi-square analyses for independent samples were conducted to investigate potential differences between the 2 cohorts within the validation populations, with regard to both the whiplash CPR variables as well as additional baseline and background variables. Chi-square analysis was also performed to examine the possible differences in recovery rates between the 2 cohorts.

Finally, a descriptive analysis was used to summarize feedback from the acceptability survey.

\section{Sample Size}

If intervals based on a $95 \%$ confidence level were constructed from at least 71 samples drawn from a population with a PPV proportion of $55 \%$, where the distance from $55 \%$ to the lower limit was $10.5 \%$, then $95 \%$ of these intervals would contain the actual population proportion. The calculations were based on PPV percent statistics reported for the whiplash 


\begin{tabular}{|c|c|c|c|}
\hline \multirow{2}{*}{$\begin{array}{l}\text { TABLE } 3 \\
\text { Factor } \\
\end{array}$} & \multirow{3}{*}{$\begin{array}{c}\begin{array}{c}\text { Validation Participants } \\
(\mathbf{n}=\mathbf{1 0 1})^{*}\end{array} \\
31.5 \pm 18.5\end{array}$} & \multirow{2}{*}{\multicolumn{2}{|c|}{$\begin{array}{l}\text { PARTICIPANTS IN THE } \\
\text { IVATION STUDIES } \\
\begin{array}{c}\text { Derivation Participants } \\
(n=262)^{*}\end{array}\end{array}$}} \\
\hline & & & \\
\hline Initial NDI (0-100) & & $32.9 \pm 17.5$ & .475 \\
\hline Age, y & $34.2 \pm 10.7$ & $37.1 \pm 14.2$ & .034 \\
\hline PDS hyperarousal subscale (0-15) & $4.3 \pm 3.9$ & $4.8 \pm 3.8$ & .271 \\
\hline Neck range of motion, deg' & $191.2 \pm 53.5$ & $201.4 \pm 63.4$ & .169 \\
\hline Initial visual analog scale for pain (0-10) & $3.5 \pm 2.1$ & $4.2 \pm 2.1$ & .005 \\
\hline Cold pain threshold, ${ }^{\circ} \mathrm{C}$ & $13.2 \pm 7.7$ & $14.4 \pm 7.7$ & .274 \\
\hline \multicolumn{4}{|c|}{$\begin{array}{l}\text { Abbreviations: NDI, Neck Disability Index; PDS, Posttraumatic Stress Diagnostic Scale. } \\
\text { *Values are mean } \pm S D \text {. } \\
\text { 'Sum of left and right neck rotation, flexion, and extension. }\end{array}$} \\
\hline
\end{tabular}

\begin{tabular}{|c|c|c|}
\hline \multirow[t]{2}{*}{$\begin{array}{r}\text { Participants Class } \\
\text { AT } 6 \text { Months FOR }\end{array}$} & \multirow[t]{2}{*}{$\begin{array}{l}\text { IEd By Recov } \\
\text { EACH STUdy P }\end{array}$} & \multirow[b]{2}{*}{$\begin{array}{l}\text { Derivation Participants } \\
\qquad(n=262)\end{array}$} \\
\hline & & \\
\hline Fully recovered (NDI, $\leq 10 \%)$ & $51(50)$ & $120(46)$ \\
\hline Continued mild to moderate pain and disability (NDI, 11\%-29\%) & $27(27)$ & $73(28)$ \\
\hline Ongoing moderate/severe pain and disability (NDI, $\geq 30 \%$ ) & $23(23)$ & $69(26)$ \\
\hline $\begin{array}{l}\text { Abbreviation: NDI, Neck Disability Index. } \\
{ }^{*} \text { Values are } n(\%) \text {. }\end{array}$ & & \\
\hline
\end{tabular}

CPR derived by Ritchie et al, ${ }^{26}$ where PPV was estimated to range from $55 \%$ (the lowest reported $95 \%$ confidence value for a PPV) and the smallest reported distance of $10.5 \%$ to a lower $95 \%$ confidence limit. The calculation allows for the worst PPV outcome with high expectations of accuracy. If the PPV were greater than $55 \%$ or accuracy less stringent, then a smaller sample size would suffice. Thus, 101 participants available for the current study met this requirement.

\section{RESULTS}

D ATA WERE ANALYZED FROM 101 INdividuals involved in 2 independent cohort studies. Six-month data applicable to the validation of the whiplash CPR were available for $95 \%(n=53)$ of cohort 1 participants and for $92 \%(\mathrm{n}=$ 48) of cohort 2 participants. ${ }^{7,14}$

\section{Whiplash CPR External Validation}

The PPV for the pathway of ongoing moderate/severe pain and disability for the validation population was $90.9 \%$, which is greater than the derivation PPV of $71.4 \%{ }^{26}$ (TABLE 1). The Hosmer-Lemeshow test resulted in a $P$ value of $.649\left(\chi^{2}\right.$ $=5.980, d f=8$ ), indicating support for the model. The very high specificity indicates that almost all of those who did not have moderate/severe disability at 6 months did not meet the 3-factor criteria. As a result, an individual who met the 3 -factor criteria was likely to experience ongoing moderate/severe pain and disability. However, the lower sensitivity indicates that some of the individuals who had ongoing moderate/severe pain and disability did not meet the criteria. The positive LR of 33.9 indicates a very large shift in probability ${ }^{13}$; however, the large $\mathrm{CI}$ indicates a lower degree of precision.
The PPV for the fully recovered pathway with the validation population was $80.0 \%$, slightly better than the PPV for the derivation cohort $(70.7 \%)^{26}$ (TABLE 2). The Hosmer-Lemeshow test resulted in a $P$ value of $.081\left(\chi^{2}=14.042, d f=8\right)$, indicating support for the model. The very high specificity indicates that most of those who had some disability did not meet the 2-factor criteria. As a result, an individual who met these criteria was likely to recover. The moderate sensitivity, however, indicates that some individuals who did not meet the criteria had varied recovery pathways, including full recovery. A positive LR between 2 and 5 represents a small but sometimes meaningful shift in probability. ${ }^{13}$

\section{Validation and Derivation Populations}

The results of independent $t$ tests showed that the derivation and validation populations differed significantly at baseline in terms of age and initial pain levels as assessed with a VAS (TABLE 3). However, etasquared showed that the magnitudes of the differences in the means for both age and initial VAS were small and therefore unlikely to be clinically significant. Chi-square analysis showed no difference between the proportion of women in the derivation $(\mathrm{n}=$ $169 / 262$ ) and the validation populations (n $=67 / 101)\left(\chi^{2}=0.108, d f=1, P=.74\right)$.

The validation population had recovery rates similar to those of the established prevalence ${ }^{15,27}$ and to the derivation cohort ${ }^{26}$ at 6 months: $50 \%(\mathrm{n}=51)$ were fully recovered, $27 \%(\mathrm{n}=27)$ continued to experience milder levels of disability, and $23 \%(\mathrm{n}=23$ ) experienced ongoing moderate/severe pain and disability (TABLE 4). Chi-square analysis showed that there were no significant differences in the proportion of participants who fully recovered or those who experienced ongoing moderate/severe pain and disability between the validation and derivation study participants $\left(\chi^{2}=0.74, d f=2, P=.69\right)$.

\section{Validation Cohorts}

The results of independent-sample $t$ tests showed no significant differences 


\begin{tabular}{|c|c|c|c|}
\hline TABLE 5 & $\begin{array}{l}\text { RISONS BET } \\
\text { TICIPANTS I }\end{array}$ & $\begin{array}{l}\text { N THE } 2 \text { CoH } \\
\text { E PRESENT S }\end{array}$ & \\
\hline Factor & Cohort $1(n=53)^{*}$ & Cohort $2(n=48)^{*}$ & $P$ Value \\
\hline Initial NDI (0-100) & $33.8 \pm 19.6$ & $29.0 \pm 17.1$ & .20 \\
\hline Age, y & $33.4 \pm 9.4$ & $35.2 \pm 11.9$ & .393 \\
\hline PDS hyperarousal subscale (0-15) & $3.9 \pm 4.1$ & $4.8 \pm 3.7$ & .281 \\
\hline Neck range of motion, deg ${ }^{\dagger}$ & $195.9 \pm 50.3$ & $186.0 \pm 56.9$ & .356 \\
\hline Initial visual analog scale for pain (0-10) & $3.6 \pm 2.3$ & $3.3 \pm 1.9$ & .516 \\
\hline Cold pain threshold, ${ }^{\circ} \mathrm{C}$ & $13.3 \pm 7.9$ & $13.1 \pm 7.6$ & .893 \\
\hline \multicolumn{4}{|c|}{$\begin{array}{l}\text { Abbreviations: NDI, Neck Disability Index; PDS, Posttraumatic Stress Diagnostic Scale. } \\
{ }^{*} \text { Values are mean } \pm S D \text {. } \\
{ }^{+} \text {Sum of left and right neck rotation, flexion, and extension. }\end{array}$} \\
\hline
\end{tabular}

between the 2 cohorts in the baseline variables examined (TABLE 5). Chi-square analysis showed that there were significantly more women in cohort 1 ( $\mathrm{n}$ $=41 / 53)$ compared with cohort $2(\mathrm{n}=$ $26 / 48)\left(\chi^{2}=6.07, d f=1, P=.014\right)$.

Chi-square analysis showed that there were no significant differences in the proportion of participants who fully recovered and those who experienced ongoing moderate/severe pain and disability between the validation study cohorts $\left(\chi^{2}=2.10, d f=2, P=.35\right)$. Hence, it was deemed appropriate to externally validate the whiplash CPR with these cohorts.

\section{Preliminary Feedback:}

\section{Clinician Acceptability}

Twenty-six (31\%) physical therapists and $2(3 \%)$ chiropractors returned the clinician acceptability survey. Due to the very small number of responding chiropractors, these responses were not included in the descriptive summary of feedback. Of the responding physical therapists, 11 were men and 15 were women. Respondents reported that 1 to 30 patients with a whiplash injury were seen in their practice per month. Collation of data on clinical acceptability showed that all respondents agreed or strongly agreed that the whiplash CPR gathered relevant information and that it was understandable for clinicians. Ninety-six percent $(n=25)$ agreed or strongly agreed that the whiplash CPR would be easy to use, $88 \%$ ( $\mathrm{n}=$
23) agreed that it would be understandable for patients, and $85 \%(n=22)$ agreed that it would help direct therapy. Ninetysix percent $(n=25)$ already clinically used the NDI to assess neck disability in patients with WAD. Clinicians were also asked about their preferred format for the administration of the whiplash CPR. The survey responses were reported in a written survey $(73 \%, \mathrm{n}=19)$, followed by a smartphone application survey (42\%, $n=11)$, web-based survey $(42 \%, n=11)$, and software-based survey $(23 \%, \mathrm{n}=6)$.

\section{DISCUSSION}

E XTERNAL VALIDATION CONFIRMED the reproducibility and accuracy of the recently derived dual-pathway whiplash CPR for individuals seeking health care for neck pain following a motor vehicle collision. ${ }^{26}$ The whiplash CPR consolidates existing evidence regarding prognostic factors for poor recovery and provides a tool to break down varied recovery patterns into more homogeneous subsets. The PPV of ongoing moderate/ severe pain and disability was $90.9 \%$ for individuals who were 35 years of age and older with initially higher levels of neck disability and hyperarousal symptoms. In addition, the probability of full recovery was $80.0 \%$ for younger individuals with initially lower levels of neck disability. The current study is one of only a few to validate a CPR in the area of musculo- skeletal pain and, to our knowledge, the only study to validate a CPR for patients with a whiplash injury. ${ }^{2,22}$ Application of this tool with similar patients may help clinicians to make decisions about prognosis and enable interventions to be designed to match patient subgroups.

There has been growing interest in CPRs for the assessment of patients with musculoskeletal pain, with the speculation that therapeutic benefits may be more likely to occur if subgroups of patients are identified and better matched to treatments. ${ }^{2,11,22}$ While, to our knowledge, there is only 1 other derivation-only $\mathrm{CPR}^{10}$ and 1 stratified risk assessment tool ${ }^{16}$ for individuals with a whiplash injury, there has been a surge of CPRs in the area of low back pain. ${ }^{9,11,12,23,24}$ Similar to acute whiplash, nonspecific low back pain is a heterogeneous condition with varied recovery rates, and optimal therapy remains equivocal. . $, 9,11,14,22$

Positive effects of matching therapeutic pathways to predict prognosis based on a CPR have been shown in patients with low back pain. ${ }^{12}$ Hill and colleagues ${ }^{12}$ subgrouped patients into low-, moderate-, and high-risk categories using a CPR-like prognostic screening tool. Treatments were matched to these categories and unnecessary treatment was avoided in low-risk patients, whereas medium- and high-risk patients were encouraged to access more concerted treatments, thereby improving clinical outcomes. This type of stratified treatment strategy, designed to target patient subgroups such as those identified in the whiplash CPR, may help to optimize recovery. Clinical treatment pathways need to be developed with clinical experts, particularly given the evidence suggesting that early intensive health care for individuals with acute whiplash injury may delay recovery. ${ }^{6,21}$ It may be that specific subsets of patients benefit from specific treatment strategies, whereas other patients may find the same therapies to be detrimental. To avoid unnecessary treatment and reduce practice variability, the recommendation for patients 
who meet the full recovery criteria may be minimal treatment and reassurance, whereas a targeted treatment approach involving physical therapy, psychological treatment, and possibly medication may be recommended for patients who meet the criteria for ongoing moderate/ severe pain and disability. Recommendations for individuals who do not meet the criteria for either pathway may be initial assessment with reassurance and followup as needed to ensure that recovery does take place, and to institute more targeted treatment if it does not. Randomized controlled treatment trials are needed to identify optimal treatment recommendations for each of the recovery pathways identified with the whiplash CPR.

Aligning treatment options to recovery pathways necessitates a CPR with high positive predictive probability and minimal false positives. ${ }^{2,18}$ Previous research suggests that, of individuals who experience an acute whiplash injury, approximately $25 \%$ are likely to experience ongoing moderate/severe pain and disability, and $50 \%$ are likely to fully recover. ${ }^{15,27}$ Application of the whiplash CPR provides a significantly better prediction of recovery, with $90.9 \%$ predictive probability for ongoing moderate/severe pain and disability (TABLE 1) and $80.0 \%$ predictive probability for full recovery (TABLE 2). The specificity of the whiplash CPR for the pathway of ongoing moderate/severe pain and disability was $98.7 \%$ (95\% CI: 93\%, 99\%) (TABLE 1) and $86.0 \%$ (95\% CI: $73 \%, 94 \%)$ for the pathway of full recovery (TABLE 2). These very high specificities indicate a low false-positive rate and help to rule in the condition. For example, if the patient meets the 3 -factor criteria for ongoing moderate/severe pain and disability, the patient is likely to continue to experience moderate/severe pain and disability; or, if a patient meets the 2 -factor criteria for full recovery, the patient is likely to fully recover. Likelihood ratios quantify both the direction and magnitude of the shift in probability that an individual will be positive or negative on the reference standard, in this case the NDI..$^{13}$ It is favorable to have higher LRs and to have a narrow CI (eg, $95 \% \mathrm{CI}$ ) to indicate that the estimate is precise. ${ }^{13}$ The positive LR of 33.9 for the ongoing moderate/severe pain and disability arm indicates a very large shift in probability, and the positive LR of 3.92 for the full recovery arm indicates a smaller shift in probability. The very large $95 \%$ CI for the ongoing moderate/ severe pain and disability arm indicates a lower degree of precision, whereas the narrow $95 \%$ CI for the full recovery arm indicates higher precision. Despite these positive statistical results, the whiplash CPR is a predictive tool; it is not meant to provide mutually exclusive decisions on prognosis but may be an additional tool to support clinical judgment.

Finally, a CPR will only be used if it makes clinical sense, is easy to use, there are no obvious items missing, and the items seem appropriate for the purpose of the rule. ${ }^{17,25}$ The variables within the whiplash CPR fit a biopsychosocial model of recovery, thereby confirming current evidence about recovery from an acute whiplash injury. The simple, 3 -step whiplash CPR is designed to be easily completed by the patient and treating clinician. The NDI, the first step, is an outcome measure that is readily available, and $96 \%(\mathrm{n}=25)$ of the responding clinicians were already using the NDI to assess neck disability in patients with a whiplash injury. In a written format, the clinician will need to calculate the score on the NDI. If the NDI is $40 \%$ or greater, the patient should then complete the 5-question PDS subscale to assess hyperarousal symptoms, and the clinician would simply calculate the total. The 5-question subscale used in the present study is part of the PDS, a valid instrument designed to help with both the detection and symptomatic evaluation of posttraumatic stress disorder symptoms. ${ }^{8}$ While there is a cost associated with using the entire instrument, the 5-question hyperarousal subscale asks generic questions about arousal symptoms and is very similar to other available tools, for example, the hyperarousal items of the Impact of Event Scale-Revised, ${ }^{34}$ a free and easily accessible questionnaire. It would thus not be difficult for clinicians to use the 5 hyperarousal symptom items independently of the entire PDS questionnaire.

Although the sample of clinicians surveyed was small, the majority agreed that the whiplash CPR gathered relevant information, would be easy to use, would be understandable for both clinicians and patients, and would help direct therapy. Future studies should gather additional information about acceptability from a wider range of clinicians, including general practitioners and those involved in the acute care of individuals following a whiplash injury, to ensure the acceptability of the whiplash CPR.

The current study was the first of a recommended series of studies needed to comprehensively validate a CPR. As such, there are several limitations to the study. First, although the data were collected prospectively in a new patient cohort, predictive validity was assessed through a retrospective secondary analysis of data. The possibility exists that the predictive validity of the whiplash CPR may be different when used prospectively. ${ }^{1,19}$ Second, this external validation included patients classified as WAD grade II, whereas the derivation study included patients classified as WAD grades I, II, and III. Hence, although most injured people are classified as WAD grade II, the validation sample is not fully representative of the population of patients seeking health care for neck pain following a motor vehicle collision. Third, the derivation and validation of the whiplash CPR involved data from participants enrolled in research studies in Brisbane, Australia. Participants recruited for research studies may respond differently from the general public with regard to components of the whiplash CPR, and the CPR may perform differently in other countries and jurisdictions. Prospective validation with a new cohort of patients fully representative of the 
WAD population would be beneficial. ${ }^{19}$ Finally, the response rate to the clinician acceptability survey was low for physical therapists and almost nonexistent for chiropractors. Caution is needed when interpreting these data. Despite these limitations, the predictive probabilities found for each pathway through this external validation study were significantly higher than the estimated probabilities suggested in previous research and therefore provide a level of evidence sufficient for clinicians to consider using the whiplash CPR with patients similar to those in the derivation and validation studies. ${ }^{19}$

\section{CONCLUSION}

E XTERNAL VALIDATION CONFIRMED that the whiplash CPR is reproducible and accurate in predicting 2 prognostic pathways following an acute whiplash injury. Further research is needed to assess prospective validation, the impact of inclusion on practice, and to examine the efficacy of linking treatment strategies with predicted prognosis. 0

\section{KEY POINTS}

FINDINGS: The predictive probabilities found for both pathways of the whiplash CPR following external validation were significantly greater than the estimated probabilities suggested in previous research.

IMPLICATIONS: The whiplash CPR may be considered reproducible and accurate for individuals seeking health care for neck pain following a motor vehicle collision. Application of this tool with similar patients may help clinicians with decisions about prognosis and may help researchers develop targeted therapies to better match patient subgroups. CAUTION: The whiplash CPR has not been prospectively validated with patients classified as WAD grades I, II, and III outside of Brisbane, Australia. Feedback on clinical acceptability of this tool is limited to a small group of physical therapists. The wide $95 \%$ CIs for the ongoing moderate/severe pain and disability pathway indicate less-than-ideal precision.

\section{REFERENCES}

1. Beattie P, Nelson R. Clinical prediction rules: what are they and what do they tell us? Aust J Physiother. 2006;52:157-163. http://dx.doi. org/10.1016/S0004-9514(06)70024-1

2. Beneciuk JM, Bishop MD, George SZ. Clinical prediction rules for physical therapy interventions: a systematic review. Phys Ther. 2009;89:114-124. http://dx.doi.org/10.2522/ ptj.20080239

3. Carroll LJ, Holm LW, Hogg-Johnson S, et al. Course and prognostic factors for neck pain in whiplash-associated disorders (WAD): results of the Bone and Joint Decade 2000-2010 Task Force on Neck Pain and Its Associated Disorders. J Manipulative Physiol Ther. 2009;32:S97-S107. http://dx.doi.org/10.1016/j. jmpt.2008.11.014

4. Childs JD, Cleland JA. Development and application of clinical prediction rules to improve decision making in physical therapist practice. Phys Ther. 2006;86:122-131.

5. Cleland JA, Childs JD, Fritz JM, Whitman JM, Eberhart SL. Development of a clinical prediction rule for guiding treatment of a subgroup of patients with neck pain: use of thoracic spine manipulation, exercise, and patient education. Phys Ther. 2007;87:9-23. http://dx.doi. org/10.2522/ptj.20060155

6. Côté P, Hogg-Johnson S, Cassidy JD, Carroll L, Frank JW, Bombardier C. Early aggressive care and delayed recovery from whiplash: isolated finding or reproducible result? Arthritis Rheum. 2007;57:861-868. http://dx.doi.org/10.1002/ art.22775

7. Elliott J, Pedler A, Kenardy J, Galloway G, Jull $G$, Sterling M. The temporal development of fatty infiltrates in the neck muscles following whiplash injury: an association with pain and posttraumatic stress. PLoS One. 2011;6:e21194. http://dx.doi.org/10.1371/journal.pone.0021194

8. Foa E. Posttraumatic Stress Diagnostic Scale Manual. Minneapolis, MN: National Computer Systems; 1995.

9. Hancock MJ, Maher CG, Latimer J, Herbert RD, McAuley JH. Can rate of recovery be predicted in patients with acute low back pain? Development of a clinical prediction rule. Eur J Pain. 2009;13:51-55. http://dx.doi.org/10.1016/j. ejpain.2008.03.007

10. Hartling L, Pickett W, Brison RJ. Derivation of a clinical decision rule for whiplash associated disorders among individuals involved in rear-end collisions. Accid Anal Prev. 2002;34:531-539.

11. Haskins R, Rivett DA, Osmotherly PG. Clinical prediction rules in the physiotherapy man- agement of low back pain: a systematic review. Man Ther. 2012;17:9-21. http://dx.doi. org/10.1016/j.math.2011.05.001

12. Hill JC, Whitehurst DG, Lewis M, et al. Comparison of stratified primary care management for low back pain with current best practice (STarT Back): a randomised controlled trial. Lancet. 2011;378:1560-1571. http://dx.doi.org/10.1016/ S0140-6736(11)60937-9

13. Jaeschke R, Guyatt GH, Sackett DL. Users' guides to the medical literature. III. How to use an article about a diagnostic test. B. What are the results and will they help me in caring for my patients? The EvidenceBased Medicine Working Group. JAMA. 1994;271:703-707. http://dx.doi.org/10.1001/ jama.1994.03510330081039

14. Jull G, Kenardy J, Hendrikz J, Cohen M, Sterling M. Management of acute whiplash: a randomized controlled trial of multidisciplinary stratified treatments. Pain. 2013;154:1798-1806. http://dx.doi.org/10.1016/j.pain.2013.05.041

15. Kamper SJ, Rebbeck TJ, Maher CG, McAuley $\mathrm{JH}$, Sterling M. Course and prognostic factors of whiplash: a systematic review and metaanalysis. Pain. 2008;138:617-629. http://dx.doi. org/10.1016/j.pain.2008.02.019

16. Kasch $\mathrm{H}$, Kongsted A, Qerama E, Bach FW, Bendix T, Jensen TS. A new stratified risk assessment tool for whiplash injuries developed from a prospective observational study. BMJ Open. 2013;3:e002050. http://dx.doi. org/10.1136/bmjopen-2012-002050

17. Laupacis A, Sekar N, Stiell IG. Clinical prediction rules. A review and suggested modifications of methodological standards. JAMA. 1997;277:488-494. http://dx.doi.org/10.1001/ jama.1997.03540300056034

18. MacDermid JC, Walton DM, Avery S, et al. Measurement properties of the Neck Disability Index: a systematic review. J Orthop Sports Phys Ther. 2009;39:400-417. http://dx.doi. org/10.2519/jospt.2009.2930

19. McGinn TG, Guyatt GH, Wyer PC, Naylor CD, Stiell IG, Richardson WS. Users' guides to the medical literature: XXII: how to use articles about clinical decision rules. Evidence-Based Medicine Working Group. JAMA. 2000;284:7984. http://dx.doi.org/10.1001/jama.284.1.79

20. Pallant J. SPSS Survival Manual: A Step by Step Guide to Data Analysis Using SPSS for Windows (Version 12). 2nd ed. Crows Nest, Australia: Allen \& Unwin; 2005.

21. Pape E, Hagen KB, Brox JI, Natvig B, Schirmer $H$. Early multidisciplinary evaluation and advice was ineffective for whiplash-associated disorders. Eur J Pain. 2009;13:1068-1075. http://dx.doi.org/10.1016/j.ejpain.2008.12.006

22. Patel S, Friede T, Froud R, Evans DW, Underwood M. Systematic review of randomized controlled trials of clinical prediction rules for physical therapy in low back pain. Spine (Phila Pa 1976). 2013;38:762-769. http://dx.doi. org/10.1097/BRS.0b013e31827b158f 
23. Puentedura EJ, Cleland JA, Landers MR, Mintken PE, Louw A, Fernández-de-las-Peñas C. Development of a clinical prediction rule to identify patients with neck pain likely to benefit from thrust joint manipulation to the cervical spine. J Orthop Sports Phys Ther. 2012;42:577592. http://dx.doi.org/10.2519/jospt.2012.4243

24. Rabin A, Shashua A, Pizem K, Dickstein R, Dar $G$. A clinical prediction rule to identify patients with low back pain who are likely to experience short-term success following lumbar stabilization exercises: a randomized controlled validation study. J Orthop Sports Phys Ther. 2014;44:6-18. http://dx.doi.org/10.2519/ jospt.2014.4888

25. Reilly BM, Evans AT. Translating clinical research into clinical practice: impact of using prediction rules to make decisions. Ann Intern Med. 2006;144:201-209. http://dx.doi. org/10.7326/0003-4819-144-3-20060207000009

26. Ritchie C, Hendrikz J, Kenardy J, Sterling M. Derivation of a clinical prediction rule to identify both chronic moderate/severe dis- ability and full recovery following whiplash injury. Pain. 2013;154:2198-2206. http://dx.doi. org/10.1016/j.pain.2013.07.001

27. Sterling M, Hendrikz J, Kenardy J. Compensation claim lodgement and health outcome developmental trajectories following whiplash injury: a prospective study. Pain. 2010;150:22-28. http://dx.doi.org/10.1016/j. pain.2010.02.013

28. Sterling M, Jull G, Vicenzino B, Kenardy J. Sensory hypersensitivity occurs soon after whiplash injury and is associated with poor recovery. Pain. 2003;104:509-517. http://dx.doi. org/10.1016/S0304-3959(03)00078-2

29. Stiell IG, Wells GA. Methodologic standards for the development of clinical decision rules in emergency medicine. Ann Emerg Med. 1999;33:437-447.

30. Vandenbroucke JP, von Elm E, Altman DG, et al. Strengthening the Reporting of Observational Studies in Epidemiology (STROBE): explanation and elaboration. Epidemiology. 2007;18:805-835. http://dx.doi.org/10.1097/ EDE.0b013e3181577511
31. Vernon H, Mior S. The Neck Disability Index: a study of reliability and validity. J Manipulative Physiol Ther. 1991;14:409-415.

32. Walton DM, MacDermid JC, Giorgianni AA, Mascarenhas JC, West SC, Zammit CA. Risk factors for persistent problems following acute whiplash injury: update of a systematic review and meta-analysis. J Orthop Sports Phys Ther 2013;43:31-43. http://dx.doi.org/10.2519/ jospt.2013.4507

33. Wasson JH, Sox HC, Neff RK, Goldman L. Clinical prediction rules-applications and methodological standards. N Engl J Med. 1985;313:793-799. http://dx.doi.org/10.1056/ NEJM198509263131306

34. Weiss DS, Marmar CR. The Impact of Event Scale, revised. In: Wilson JP, Keane TM, eds. Assessing Psychological Trauma and PTSD. New York, NY: Guilford Press; 1997:399-411. WWW.JOSPT.ORG

\section{CHECK Your References With the JOSPT Reference Library}

$J O S P T$ has created an EndNote reference library for authors to use in conjunction with PubMed/Medline when assembling their manuscript references. This addition to Author and Reviewer Tools on the JOSPT website under offers a compilation of all article reference sections published in the Journal from 2006 to date as well as complete references for all articles published by JOSPT since 1979-a total of more than 20,000 unique references. Each reference has been checked for accuracy.

This resource is updated quarterly on JOSPT's website.

The JOSPT Reference Library can be found at: http://www.jospt.org/page/ authors/author_reviewer_tools 